\title{
Behavior of an Internally Confined Hollow Reinforced Concrete Column with a Polygonal Cross-Section
}

\author{
Sungwon Kim (D), Hyemin Hong and Taekhee Han *(D) \\ Coastal Development and Ocean Energy Research Center, Korea Institute of Ocean Science and Technology, \\ 385 Haeyang-ro, Yeongdo-gu, Busan 49111, Korea; swkim@kiost.ac.kr (S.K.); hyeminhong@kiost.ac.kr (H.H.) \\ * Correspondence: taekheehan@kiost.ac.kr
}

Citation: Kim, S.; Hong, H.; Han, T. Behavior of an Internally Confined Hollow Reinforced Concrete Column with a Polygonal Cross-Section. Appl. Sci. 2021, 11, 4302. https://doi.org/ 10.3390/app11094302

Academic Editor: João Carlos de Oliviera Matias

Received: 6 April 2021

Accepted: 5 May 2021

Published: 10 May 2021

Publisher's Note: MDPI stays neutra with regard to jurisdictional claims in published maps and institutional affiliations.

Copyright: (c) 2021 by the authors. Licensee MDPI, Basel, Switzerland. This article is an open access article distributed under the terms and conditions of the Creative Commons Attribution (CC BY) license (https:/ / creativecommons.org/licenses/by/ $4.0 /)$.

\begin{abstract}
The new supporting structure, internally confined hollow reinforced concrete (ICH RC), was suggested by former researchers. It maintains the material saving effect, which is the advantage of the hollow concrete structure, and it solves the brittle fracture problem of the inner wall by the inner steel pipe to make it into the 3-axis confinement state. However, until now, its design and analysis model has been limited to a circular cross-section. In this study, to expand the applicability, research and development of an ICH RC structure with a polygonal cross-section were performed. The material model was developed by defining the constraint stress in the members of the concrete and deriving a reasonable stress-strain relationship. For the column model, it was developed to predict the behavior of the polygonal ICH RC columns by analyzing the axial force-moment correlation, moment-curvature, and lateral force-displacement relationship. Each model was verified not only by comparing with the results of previous experiments but also by analyzing the results according to parameters. The maximum load and ultimate displacement values through the developed model showed the difference with the experimental results within $6 \%$ of mean error. It was verified that the proposed analytical model reasonably reflects the behavior of actual columns.
\end{abstract}

Keywords: confined concrete; polygonal cross-section; ICH RC; concrete column

\section{Introduction}

Recently, the trend of enlargement of structures, such as skyscrapers, pier for long-span bridges, and wind turbine towers, has been growing. According to Gabel [1], the number of skyscrapers over 200 meters high has been increasing (Figure 1). The increase in building height is accompanied by an increase in building weight and moment due to lateral force. The performance of a building's structural system is determined by resistance to lateral force, which increases with the building height. Various studies have been conducted on the column structure for improving the building performance. Tailor et al. [2] proposed a concrete-filled steel tube (CFST) and evaluated its seismic performance by comparing the static and dynamic behavior with a steel column. The growth of the lateral force with an increase in building height is closely related to the outline of the building. Elshaer et al. [3] conducted a study related to wind load at the building edge according to the shape of the buildings. Bai et al. [4] conducted a study about thin-walled CFST columns to enhance seismic collapse performance of high-rise steel frames.

In the case of bridges, both the span and height have been increased, and several studies have been conducted on piers and girder-supported bridges $[5,6]$. In the case of a wind tower, the installation height of the turbine has been increased to obtain highquality wind, which increases the power generation efficiency; hence, the slenderness ratio increases due to an increase in the tower height to support the wind turbine [7]. This increase in slenderness can cause problems due to the reduced safety of the wind tower. According to Ma et al., 48 tower accidents collapsed by various causes during the 16 years since 2000 [8]. A wind turbine tower also broke by the buckling failure in $2019[9,10]$. 


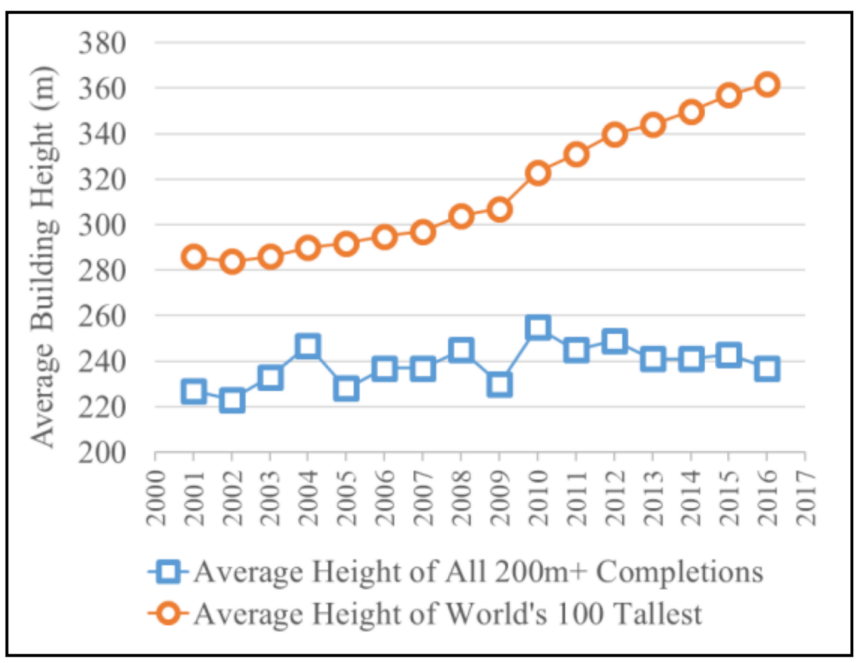

Figure 1. Average height of the tallest buildings.

Han et al. [11] proposed a new column-type internally confined hollow reinforced concrete (ICH RC) structure to improve the safety and performance of these large structures. In the case of RC columns that can reduce the column weight and save material usage, it is possible to use the cross-section more effectively than the solid reinforced concrete column. However, it might exhibit low ductility behavior due to the brittle fracture inside the column. The ICH RC structure is a structure in which a steel pipe is inserted into the hollow surface to prevent the brittle fracture of the inner wall of the hollow RC member to make the concrete into a three-axis confinement state (Figure 2). The ICH RC structure was found to be more effective than conventional RC columns in terms of weight and strength [11]. In addition, the ICH RC columns showed better resistance to strength and bending moments when compared to steel columns of the same diameter [12]. The ICH RC structure can be applied to the supporting structures of skyscrapers, super long-span bridges, and new types of wind towers, and it can contribute to safety improvement of the structure. To date, the nonlinear behavior analysis of a circular cross-section ICH RC structure has been extensively researched and applied to a wind tower, but ICH RC columns having polygonal cross-sections have not been researched [13].

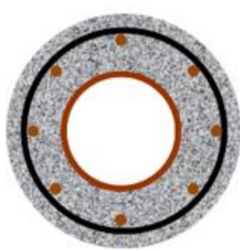

(a)

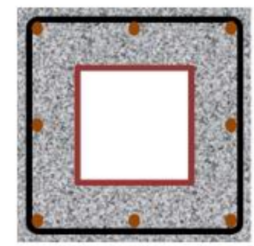

2...............

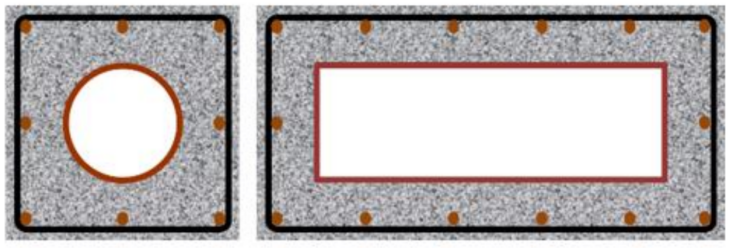

(b)

- Longitudinal reinforcement,

Transverse reinforcement, Steel tube, 圆 Concrete.

Figure 2. ICH RC structure: (a) circular cross-section ICH RC; (b) polygonal cross-section ICH RC.

In this study, an ICH RC member with polygonal cross-section is introduced, and a nonlinear concrete model, as well as a column model considering the confining effect of concrete, is developed for accurate analysis of ICH RC columns having a polygonal cross-section. The developed model can derive an accurate analytical value of the ICH $\mathrm{RC}$ structure when it applies to supporting structures such as super long-span bridges, high-rise buildings, and wave dissipating blocks. 


\section{Analytical Model}

\subsection{Concrete Model}

\subsubsection{Failure Mode}

A linearized material model is generally applied for analyzing reinforced concrete columns. A nonlinear concrete model plays an important role in obtaining more accurate results for the analysis of a polygonal ICH RC column. In this study, a nonlinear concrete model for analyzing the polygonal ICH RC column was developed by referring to the concrete model proposed by Han et al. [11]. They defined the three failure modes of a circular ICH RC column under the confining condition of concrete if the concrete was under biaxial or triaxial confinement. The suggested failure modes are expressed Equations (1)-(3).

$$
\begin{aligned}
& f_{\text {tube }}>f_{\text {lim }}=\operatorname{smaller}\left(f_{y h}, f_{b t} \text { or } f_{b k}\right): \text { Failure mode } 1 \\
& f_{\text {tube }}<f_{\text {lim }}=\operatorname{smaller}\left(f_{y h}, f_{b t} \text { or } f_{b k}\right): \text { Failure mode } 2 \\
& f_{\text {tube }}=f_{\text {lim }}=\operatorname{smaller}\left(f_{y h}, f_{b t} \text { or } f_{b k}\right): \text { Failure mode } 3
\end{aligned}
$$

The inner tube failed before the failure of the transverse reinforcement in failure mode 1 , and the concrete in the polygonal ICH RC column was triaxially confined until the failure of the inner tube. Then, the concrete was on the biaxial confined status because the confining effect was no more applied to the inside of the column. For the second failure mode, which is the inverse case of failure mode 1, the concrete sustained a triaxially confined status until the failure of transverse reinforcement. In this failure mode, the failure of the column member depended on the yielding of the transverse reinforcement. The last failure mode does not conventionally occur and can be assumed to be similar to the second failure mode.

\subsubsection{Equilibrium in A Polygonal ICH RC Column}

Figures 3 and 4 show free-body diagrams of the cross-section of a polygonal ICH $\mathrm{RC}$ column when an axial load acts on the concrete only. The polygonal ICH RC can be of a rectangular cross-section, so the confining pressure should be considered for the horizontal ( $x$-axis) and vertical ( $y$-axis) directions. The confining pressure in the triaxially confined status and the stress acting on the inner tube can be derived from Equations (2)-(8) from the free-body diagrams shown in Figures 3 and 4, respectively. In case the triaxial confinement status is maintained, the confining pressure is the same as that for a solid RC column. When the inner tube fails and the concrete is biaxially confined, it is the same as the condition of a solid RC. In this case, the confining pressure for each direction is derived from Equations (9)-(11), and $f_{l r-x}$ and $f_{l r-y}$ can be assumed to be 0 .

$$
\begin{gathered}
f_{l r-x}=\frac{2 f_{y h} A_{s p}}{d_{c} s} \\
f_{l r-y}=\frac{2 f_{y h} A_{s p}}{b_{c} s} \\
f_{l}=\frac{1}{2}\left(f_{l r-x}+f_{l r-y}\right) \\
f_{t u b e-x}=\frac{f_{l r-x} d_{c i}}{2 t} \\
f_{t u b e-y}=\frac{f_{l r-y} b_{c i}}{2 t} \\
f_{l c-x}=\frac{2 f_{y h} A_{s p}}{\left(d_{c}-d_{c i}\right) s} \\
f_{l c-y}=\frac{2 f_{y h} A_{s p}}{\left(b_{c}-b_{c i}\right) s}
\end{gathered}
$$




$$
f_{l c}=\frac{1}{2}\left(f_{l c-x}+f_{l c-y}\right)
$$

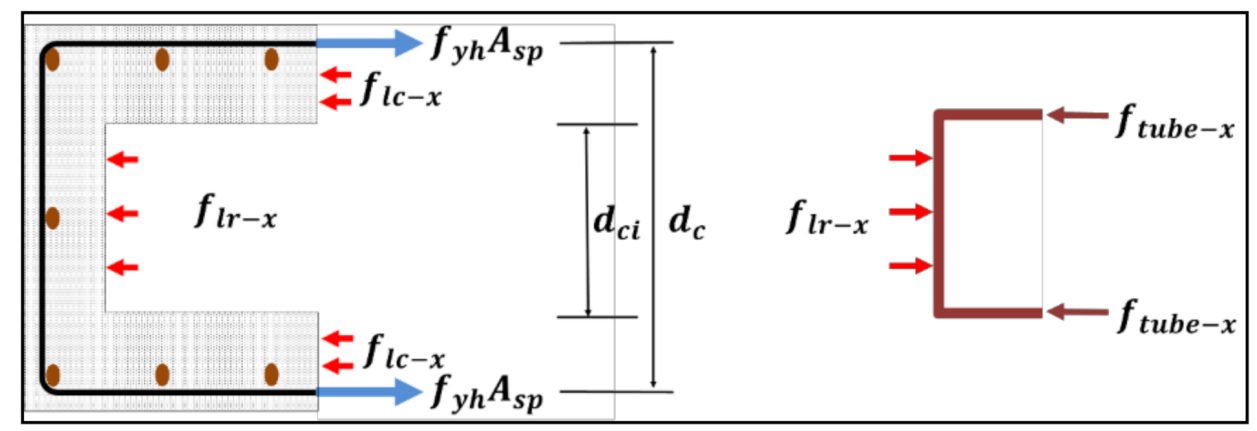

Figure 3. Confining stress on concrete in an ICH RC column in x-direction: (left) FBD for concrete and reinforcement; (right) FBD for internal tube.

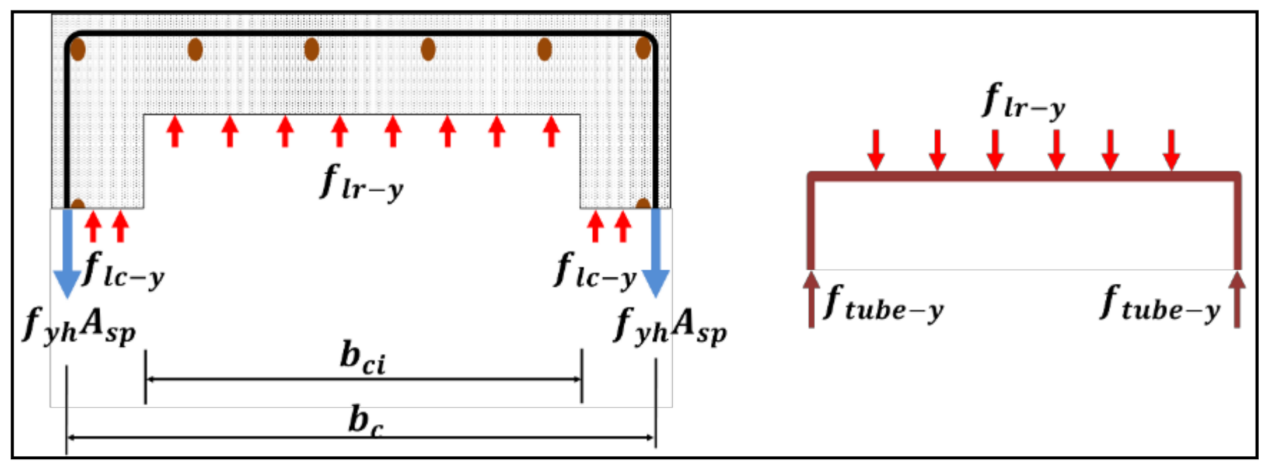

Figure 4. Confining stress on concrete in an ICH RC column in y-direction: (left) FBD for concrete and reinforcement; (right) FBD for internal tube.

The yield strength, bending strength, and buckling strength of a steel tube are mainly dependent on the tube thickness, and the failure modes of the ICH RC column member can be derived by controlling the inner tube thickness. The stress acting on the inner tube must be smaller than the yield stress of the inner tube to induce the failure of the transverse reinforcement before the inner tube fails (Equations (12)-(13)). The minimum inner tube thickness of the ICH RC column member to avoid failure due to confining pressure can be determined from Equation (14).

$$
\begin{gathered}
f_{\text {tube-x }}=\frac{d_{c i} f_{y h} A_{s p}}{d_{c} s t}<f_{y t} \\
f_{\text {tube-y }}=\frac{b_{c i} f_{y h} A_{s p}}{b_{c} s t}<f_{y t} \\
t>\operatorname{bigger}\left(\frac{d_{c i} f_{y h} A_{s p}}{d_{c} s t}=t_{\text {yield }-x}, \frac{b_{c i} f_{y h} A_{s p}}{b_{c} s t}=t_{\text {yield }-y}\right)
\end{gathered}
$$

The inner tube of a polygonal ICH RC is pressured uniformly by the confining effect of concrete from the outside to the inside. This confining pressure bends the inner tube, and the strength of the tube must be larger than the bending stress induced by the confining pressure to sustain a triaxial confining effect without the failure of the inner tube. The American Wood Council [14] suggested the equations for determining the maximum bending moment at the center of the beam fixed at both ends, and the maximum bending 
stress of the inner tube can be calculated by applying Equations (15) and (16). The required minimum inner tube thickness can be calculated from Equation (17).

$$
\begin{gathered}
f_{b t-x}=\frac{d_{c i} f_{y h} A_{s p}}{4 d_{c} s t}<f_{y t} \\
f_{b t-y}=\frac{b_{c i} f_{y h} A_{s p}}{4 b_{c} s t}<f_{y t} \\
t>\operatorname{bigger}\left(\frac{d_{c i} f_{y h} A_{s p}}{4 d_{c} s f_{y t}}=t_{b e n d-x}, \frac{b_{c i} f_{y h} A_{s p}}{4 b_{c} s f_{y t}}=t_{\text {bend }-y}\right)
\end{gathered}
$$

For the case where a polygonal ICH RC column composed of a circular inner tube is unilaterally restrained by concrete, the failure of the inner tube by buckling should be considered. In this case, it is assumed that the circular inner tube can be applied only when the external cross-section is a square. Han et al. [11] assumed that the buckling behavior of the inner tube can be considered as the snap-through behavior of a circular shallow arch because their buckled shapes are similar. Kerr and Soifer [15] suggested a buckling coefficient and applied it to estimate the buckling strength of the inner tube. The snap-through buckling strength of the inner tube can be estimated from Equation (18). To prevent the buckling failure of the inner tube before the transverse reinforcement fails, the buckling strength of the inner tube must be larger than the confining pressure acting on the concrete when the transverse reinforcement yields. This criterion can be defined as Equation (19), and the inner tube thickness for avoiding the buckling failure can be determined from Equation (20).

$$
\begin{gathered}
f_{b k}=\frac{2.27}{3} \frac{t^{2} E}{D_{i}^{2}} \\
f_{b k}=\frac{2.27}{3} \frac{t^{2} E}{D_{i}^{2}}>f_{l}=\frac{2 f_{y h} A_{s p}}{\left(b_{c o r} d_{c}\right) s} \\
t>\sqrt{\frac{6}{2.27} \frac{D_{i}^{2} f_{y h} A_{s p}}{\left(b_{c o r} d_{c}\right) E s}}=t_{b k}
\end{gathered}
$$

\subsubsection{Stress-Strain Relation}

To determine the stress-stress relation of the confined concrete in the polygonal ICH RC, the unified concrete model proposed by Mander et al. [16] was applied. They used the form of the skeleton branch stress-strain relation in compression for confined and unconfined concrete and followed the equation suggested by Popovics [17] for monotonic loading. The equation suggested by Popovics has an advantage in that it obviates the need for a separate falling branch relation.

$$
\begin{gathered}
f_{c}=\frac{f_{c c}^{\prime} x r}{r-1+x^{r}} \\
x=\frac{\varepsilon}{\varepsilon_{c c}} \\
r=\frac{E_{c}}{\left(E_{c}-E_{\mathrm{sec}}\right)} \\
E_{\mathrm{sec}}=\frac{f_{c c}^{\prime}}{\varepsilon_{c c}}
\end{gathered}
$$

The peak concrete strength for triaxially confined concrete can be calculated from Equation (25). For the biaxially confined concrete, the peak concrete strength can be 
determined from Equation (26), which was suggested by Han et al. [11]. The strain at the peak concrete strength can be calculated from Equation (27).

$$
\begin{gathered}
f_{c c}^{\prime}=f_{c}^{\prime}\left(2.254 \sqrt{\left.1+\frac{7.94 f_{l}^{\prime}}{f_{c}^{\prime}}-\frac{2 f_{l}^{\prime}}{f_{c}^{\prime}}-1.254\right)}\right. \\
f_{c c}^{\prime}=-2.75 \frac{f_{l c}^{\prime 2}}{f_{c}^{\prime}}+1.835 f_{l c}^{\prime}+f_{c}^{\prime} \\
\varepsilon_{c c}=\varepsilon_{c o}\left[1+5\left(\frac{f_{c c}^{\prime}}{f_{c}^{\prime}}-1\right)\right]
\end{gathered}
$$

Because of the internal arching between the corners, the concrete is only effectively confined in the corners and central region of the section. Therefore, $f_{l}$ should be replaced by $f_{l}^{\prime}$. The effective constant-confining pressure can be calculated from Equation (28) by using the confinement effectiveness coefficient $k_{e}$.

$$
f_{l}^{\prime}=k_{e} f_{l}
$$

\subsection{Column Model}

In this study, a column analysis model for predicting the behavior of a polygonal $\mathrm{ICH}$ $\mathrm{RC}$ column is developed based on the nonlinear concrete model described above. The developed column model can analyze axial load-bending moment interaction and lateral load-displacement of the ICH RC column. In this model, the inner tube and concrete are considered to be completely connected. In addition, the section analysis accounts for the equilibrium, strain compatibility, and material stress-strain curves, and adopts the layerby-layer technique for numerical integration of stresses [18]. In the column analysis model, different material options for the concrete and steel can be applied. Irrespective of whether the confining effect of concrete can be applied or not, the nonlinear and elastoplastic model for the steel parts, such as the inner tube and the reinforcement, can be considered. Figure 5 shows an outline of the analyzed idealized cross-section, and Figure 6 shows the applied stress-strain curves for the concrete and steel parts. The analyzing stages follow the strain distribution in Figure 7. At each stage $i$, the stress acting on the concrete, reinforcements, and inner tube is calculated, and then summated. The axial load, bending moment, and curvature at each strain step were determined from Equations (29-31).

$$
\begin{gathered}
P_{i}=P_{i}^{C C}+P_{i}^{C V}+P_{i}^{R}+P_{i}^{T} \\
M_{i}=M_{i}^{C C}+M_{i}^{C V}+M_{i}^{R}+M_{i}^{T} \\
\phi_{i}=\frac{\varepsilon_{\mathcal{c c}}}{C_{b, i}}
\end{gathered}
$$

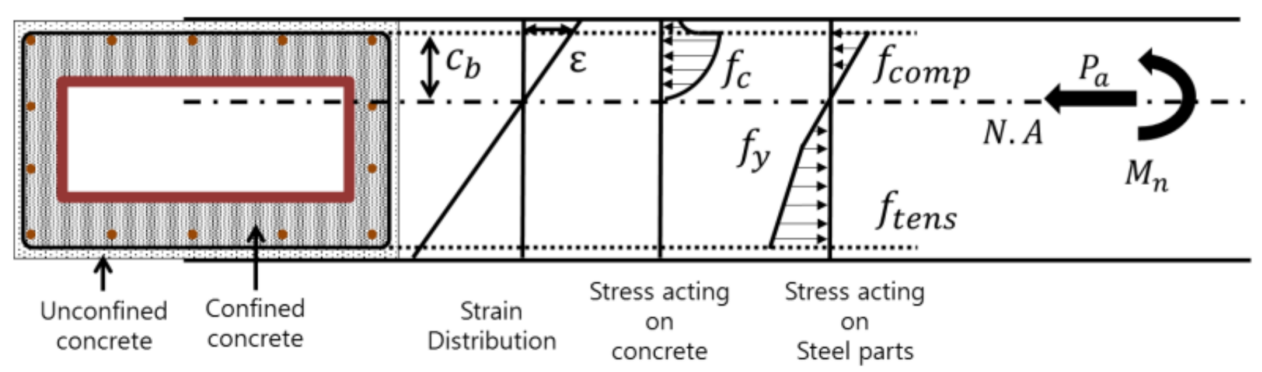

Figure 5. Section analysis using strain compatibility and layer-by-layer approach. 


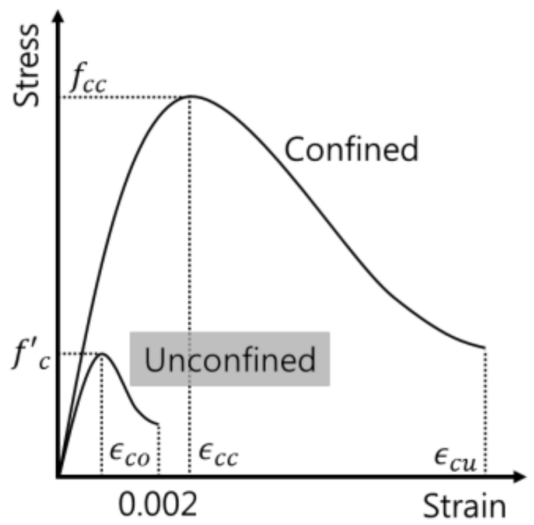

(a)

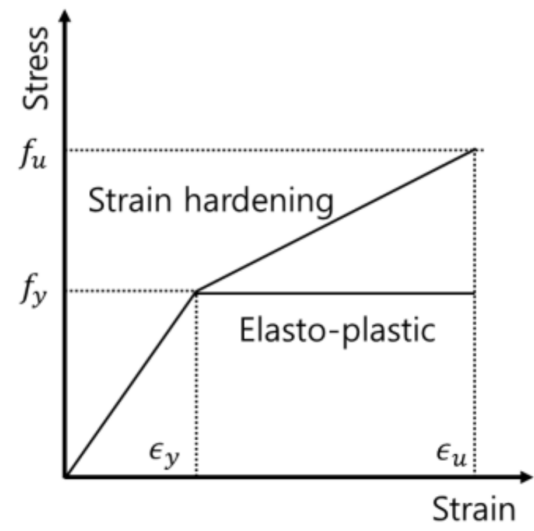

(b)

Figure 6. Idealized stress-strain curves: (a) concrete, (b) steel.

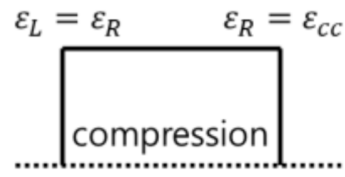

(a) Initial stage

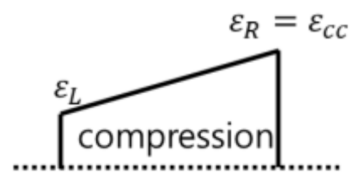

(b) Middle stage

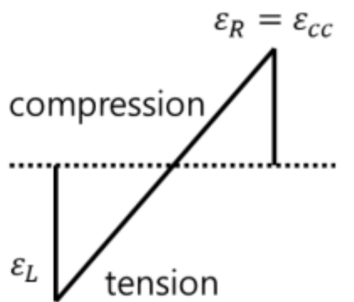

(b) Final stage

Figure 7. Stages of strain distribution.

The lateral load and displacement can be calculated using the bending moment and curvature at each strain stage. The lateral load is determined using Equation (20). The distribution of the curvature at each column height is shown in Figure 8. It is assumed that the same curvature is distributed from the column base to the height of the plastic hinge, and then, the curvature linearly decreases from the height of the plastic hinge until the top of the column at 0 . The curvature function $\phi(z)$ along the column height is shown in Equations (21) and (22). The length of the plastic hinge is determined by calculating the column height, which has a larger moment than the yield moment, assuming the moment distribution shown in Figure 8.

$$
\begin{gathered}
F_{L, i}=\frac{M_{i}}{H} \\
\phi(z)=\phi_{i}: \text { when } 0 \leq z \leq H_{p} \\
\phi(z)=\phi_{i}+\frac{\phi_{i}}{H-H_{p}}\left(z-H_{p}\right): \text { when } z>H_{p}
\end{gathered}
$$

The relation between the curvature and displacement is determined from the assumption made in Figure 9. The column is divided into n elements along the column height, and the length of each element is designated as $S_{i, j}$ and the angle with the $j$ th curvature element is labeled as $\theta_{i, j}$. Therefore, the angle of the $i$ th element is a cumulated value with previous elements, and the displacement of the elements can be calculated using it. The displacement of the $j$ th strain stage can be calculated through a summation of each displacement of all elements and can be defined as the formulation shown in Equations (35) and (36). In addition, the initial axial load is considered in the developed column analysis model using the initial strain and can be converted into initial stress. Then it is possible to calculate an initial strain corresponding thereto. In the column model, the case where one of the strains of reinforcements or the concrete reaches the respective ultimate strain is assumed as the failure of the column, and the column analysis is deemed to be finished. For the concrete 
cover, the stress is not set as 0 but set to be calculated according to the material relation shown in Equations (21)-(24) even when the ultimate strain of the concrete is exceeded. A column analysis program is coded in MATLAB using the derived equations.

$$
\begin{gathered}
\theta_{i, j}=\phi(z) \cdot S_{i . j} \\
\Delta_{i}=\sum_{j=1}^{n} \Delta_{i, j}=\sum_{j=1}^{n}\left(S_{i, j} \sum_{k=1}^{j} \theta_{i, k}\right)
\end{gathered}
$$

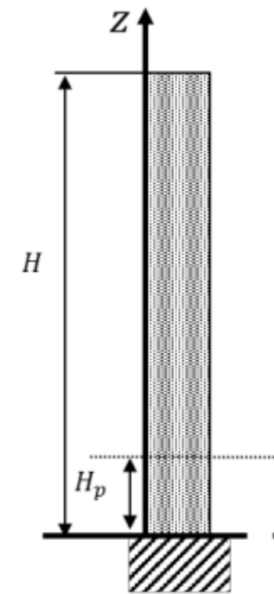

(a) Column

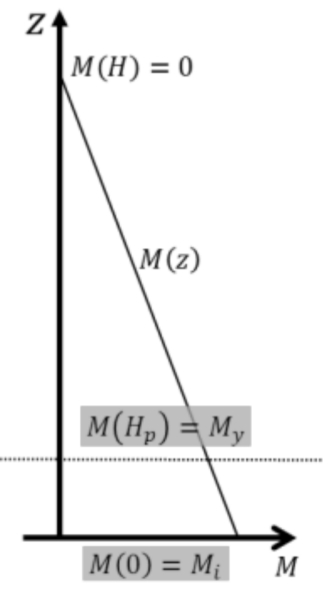

(b) Moment distribution

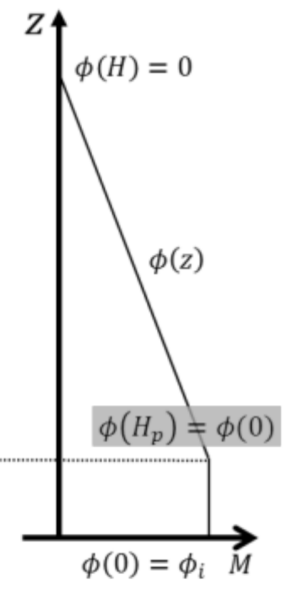

(c) Curvature distribution

Figure 8. Moment and curvature distribution.

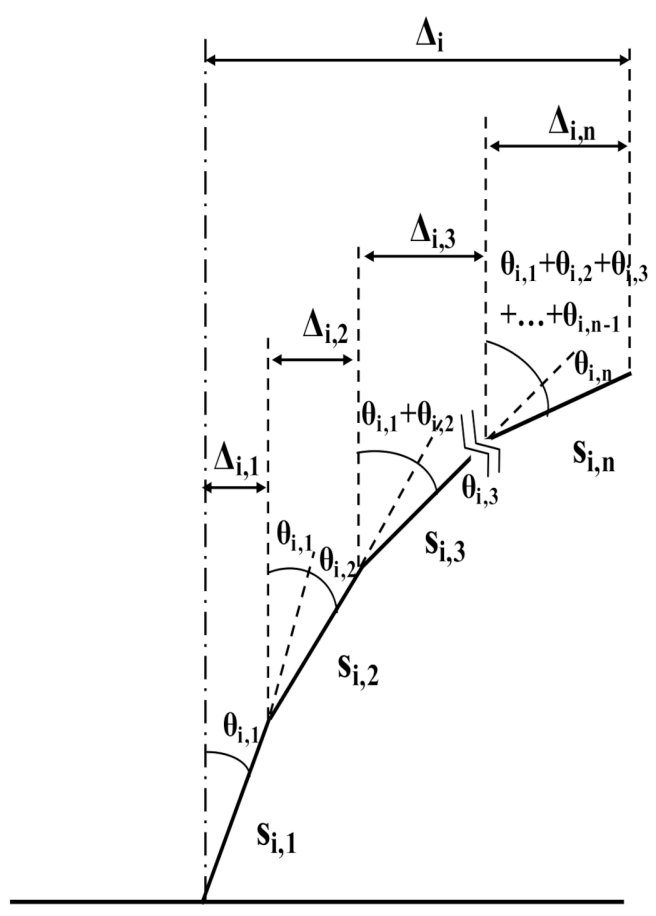

Figure 9. Calculation method of displacement.

\section{Verification}

The polygonal ICH RC is a new type of structure and hence has not been experimented with yet. Therefore, the developed column analysis program is verified by comparing its 
results with those of experiments conducted for solid RCs in previous studies [19-23]. In addition, the program is confirmed through a comparison of results according to parameters such as inner tube thickness and strength of the used concrete.

\subsection{Comparison with the Experimental Results Obtained from References}

As mentioned above, five references about the experiments of the hollow RC column are examined and compared with the results from the developed program because the polygonal ICH RC has not been studied yet. The specification of the hollow RCs is shown in Table 1. The ratios of the maximum lateral force of the columns from the experiment and the developed column model are calculated and shown in Table 1, and the lateral force-displacement relation for each case is shown in Figure 10. In the case of the maximum displacement, there is a difference in each case, but in most cases, the experimental and analytical results are similar in the early stage. In the maximum lateral force comparison obtained from the experimental results and the developed model analysis, the total error average is about $6 \%$, which confirms the accuracy of the developed material model.

Table 1. Properties of reference solid RC columns.

\begin{tabular}{|c|c|c|c|c|c|c|c|c|c|c|c|}
\hline & & \multirow{2}{*}{\multicolumn{2}{|c|}{ 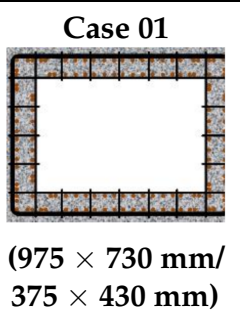 }} & \multirow{2}{*}{\multicolumn{2}{|c|}{\begin{tabular}{|l|} 
Case 02 \\
\\
$(400 \mathrm{~mm} /$ \\
$200 \mathrm{~mm})$
\end{tabular}}} & \multicolumn{2}{|c|}{ Case 03} & \multicolumn{2}{|c|}{ Case 04} & \multicolumn{2}{|c|}{ Case 05} \\
\hline & & & & & & & & & Im) & & im) \\
\hline \multicolumn{2}{|c|}{$d_{h}(\mathrm{~mm})$} & \multicolumn{2}{|c|}{10} & \multicolumn{2}{|c|}{6.05} & \multicolumn{2}{|c|}{10} & \multicolumn{2}{|c|}{12} & \multicolumn{2}{|c|}{9} \\
\hline \multicolumn{2}{|c|}{$d_{v}(\mathrm{~mm})$} & \multicolumn{2}{|c|}{16} & \multicolumn{2}{|c|}{13} & \multicolumn{2}{|c|}{16} & \multicolumn{2}{|c|}{16} & \multicolumn{2}{|c|}{19} \\
\hline \multicolumn{2}{|c|}{$s(\mathrm{~mm})$} & \multicolumn{2}{|c|}{40} & \multicolumn{2}{|c|}{124} & \multicolumn{2}{|c|}{90} & \multicolumn{2}{|c|}{100} & \multicolumn{2}{|c|}{100} \\
\hline \multicolumn{2}{|c|}{$f^{\prime}{ }_{C}(\mathrm{MPa})$} & \multicolumn{2}{|c|}{56.8} & \multicolumn{2}{|c|}{25.0} & \multicolumn{2}{|c|}{40.0} & \multicolumn{2}{|c|}{23.6} & \multicolumn{2}{|c|}{24.8} \\
\hline \multicolumn{2}{|c|}{$f_{y h}(\mathrm{MPa})$} & \multicolumn{2}{|c|}{421} & \multicolumn{2}{|c|}{421} & \multicolumn{2}{|c|}{434} & \multicolumn{2}{|c|}{320} & \multicolumn{2}{|c|}{325} \\
\hline \multicolumn{2}{|c|}{$f_{y v}(\mathrm{MPa})$} & \multicolumn{2}{|c|}{482} & & & & & & & & \\
\hline & & & & & & & & & & & \\
\hline$F_{\text {init }}$ & $\mathrm{kN})$ & & & & & & & & & & \\
\hline $\begin{array}{l}\text { Exp. } \\
(\mathrm{kN})\end{array}$ & $\begin{array}{l}\text { Anal. } \\
(\mathrm{kN})\end{array}$ & 1081 & 1040 & 184 & 177 & 213 & 243 & 192 & 196 & 115 & 124 \\
\hline $\begin{array}{r}\mathrm{R} \\
\text { (Exp. }\end{array}$ & $\begin{array}{l}\text { o } \\
\text { nal.) }\end{array}$ & & & & & & & & & & \\
\hline
\end{tabular}



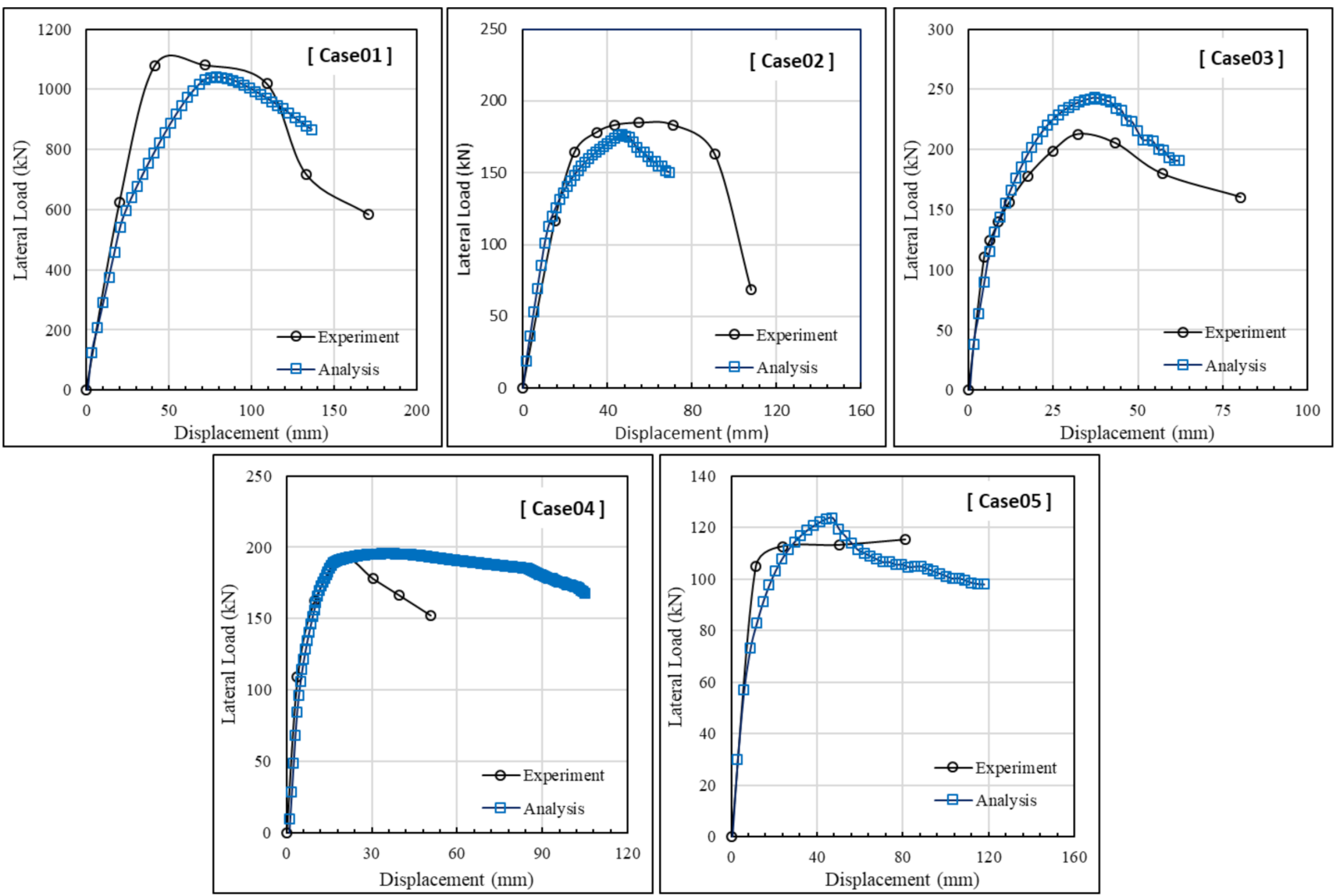

Figure 10. Results of comparisons between references and analyses.

\subsection{Behavior of Polygonal ICH RC According to Parameters}

The behavior of polygonal ICH RC columns according to parameters was analyzed using the developed column analysis model. As a parameter, the inner tube thickness and the strength of concrete were selected, and the behavior of polygonal ICH RC columns varied according to these parameters.

\subsubsection{Rectangular Cross-Section}

The behavior of the rectangular ICH RC columns was analyzed according to the change in concrete strength and inner tube thickness. Table 2 shows the material properties of the concrete and reinforcements used in the representative section and column members, as well as information on columns.

Table 2. Cross-section and specification of the rectangular ICH RC column.

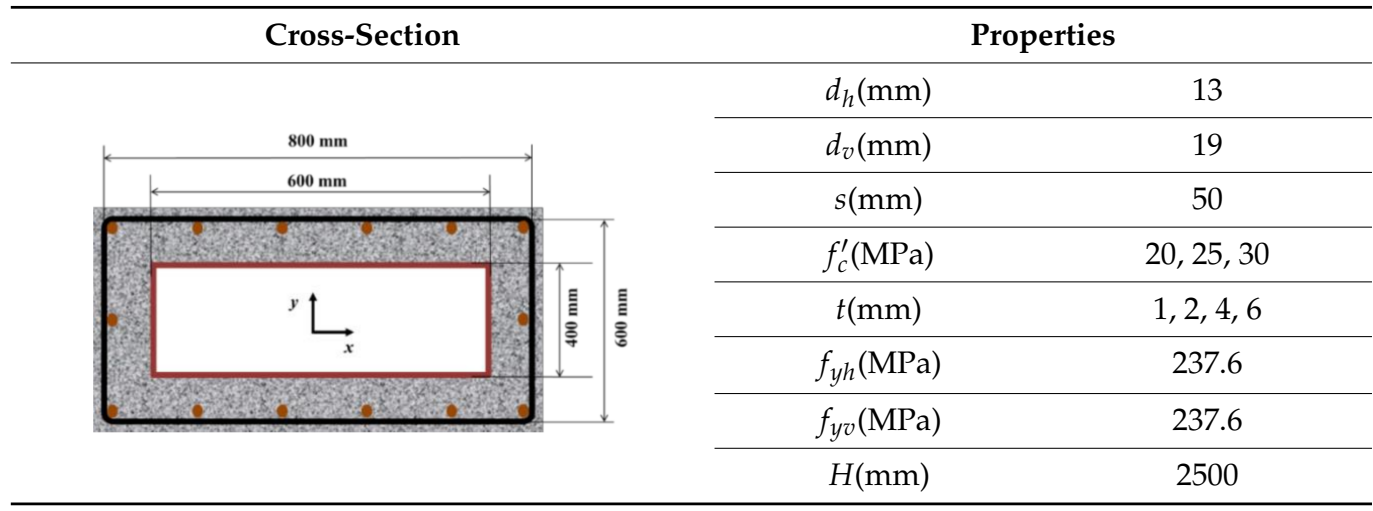


- Analysis of the axial load-bending moment

Figures 11 and 12 show the results of axial load-bending moment analysis of the rectangular ICH RC columns according to the parameters. Since the ICH RC columns of the rectangular cross-section have different lengths in transverse $(x)$ and longitudinal $(y)$ directions, the results of each analysis are separately derived by the applied load directions. In addition to the cases of concrete strengths of values 20, 25, and $30 \mathrm{MPa}$, shown in Table 2 above, the case where the $20 \mathrm{MPa}$ concrete is not confined is analyzed for confirming the confining effect. The inner tube thickness of the cases changing the strength of the concrete is set to $3 \mathrm{~mm}$, and the concrete strength of the case changing the inner tube is $25 \mathrm{MPa}$. It is assumed that there is no initial axial load.
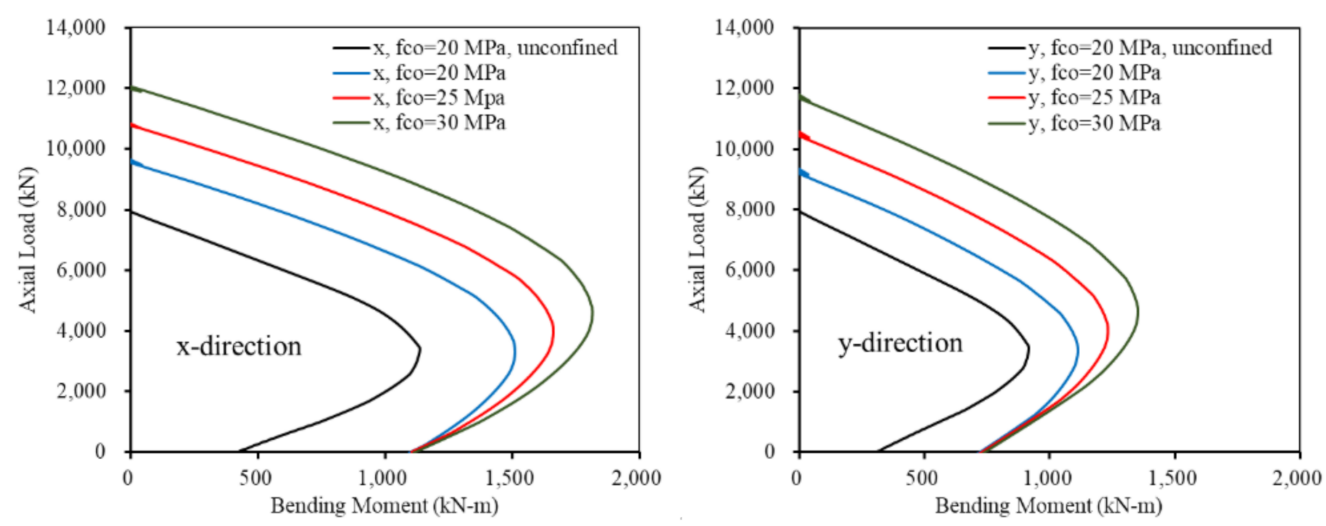

Figure 11. P-M interaction curves according to concrete strength (rectangular cross-section).
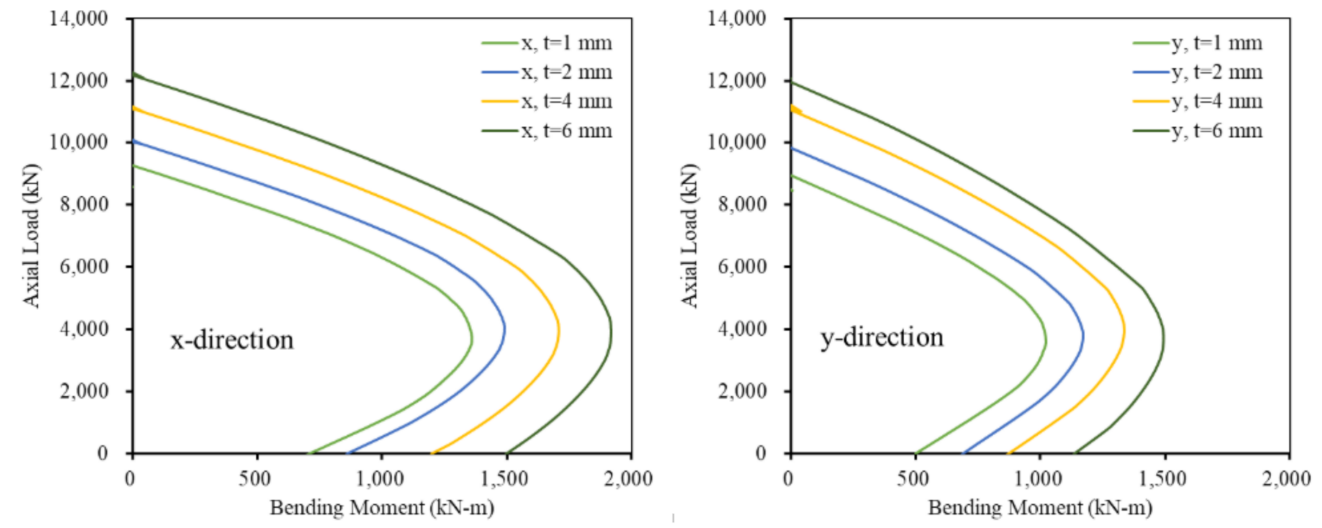

Figure 12. P-M interaction curves according to the inner tube thickness (rectangular cross-section).

The results of the P-M interaction above show that the resistance against the axial force and bending moment increases in both directions when the confining effect of concrete occurs. The maximum axial load and bending moment of confining concrete in the $x$ direction are found to be $126 \%$ and $133 \%$ of the unconfined concrete, respectively. In addition, as the concrete strength increases, the maximum axial load and bending moment increase as well. In the case of varying inner tube thickness, it is confirmed that the resistance capacity of the rectangular ICH RC column with respect to the maximum axial force and bending moment also increases in both directions as the inner tube thickness increases. In the directional comparison of the ICH RC columns with the rectangular cross-section, it can be found that the maximum bending moment with respect to the direction of the longer length in the two directions is larger.

- Analysis of the lateral load-displacement 
Figures 13 and 14 show the results of the lateral load-displacement analysis of the rectangular ICH RC columns according to the parameters. As with the P-M interaction analysis, the analytical results for each direction are separately derived.
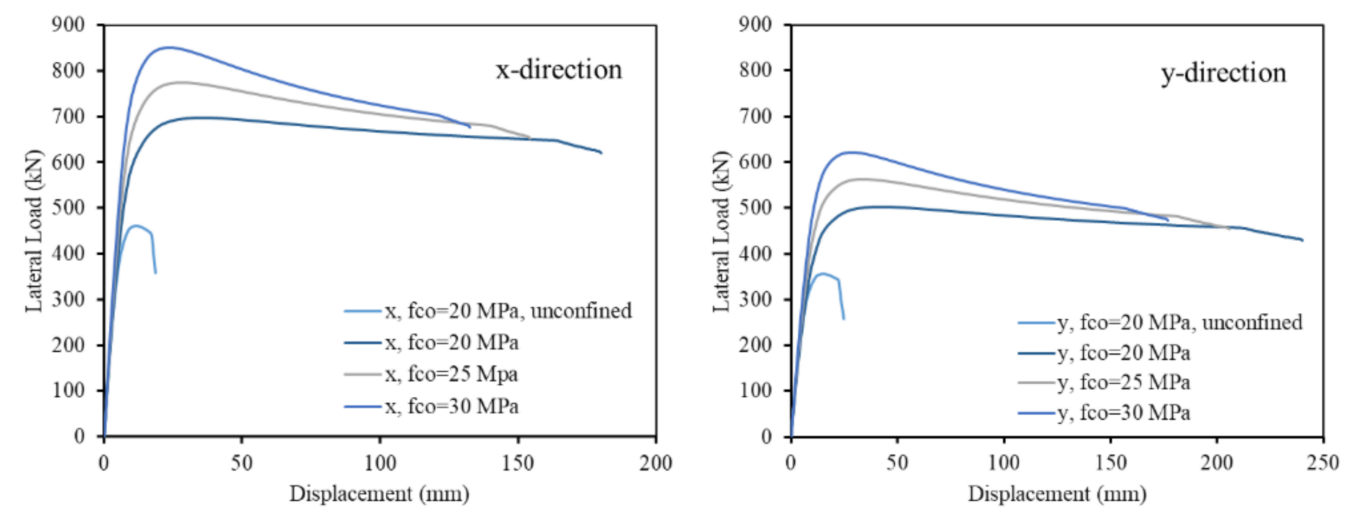

Figure 13. Lateral load-displacement curves by the concrete strength (rectangular cross-section).
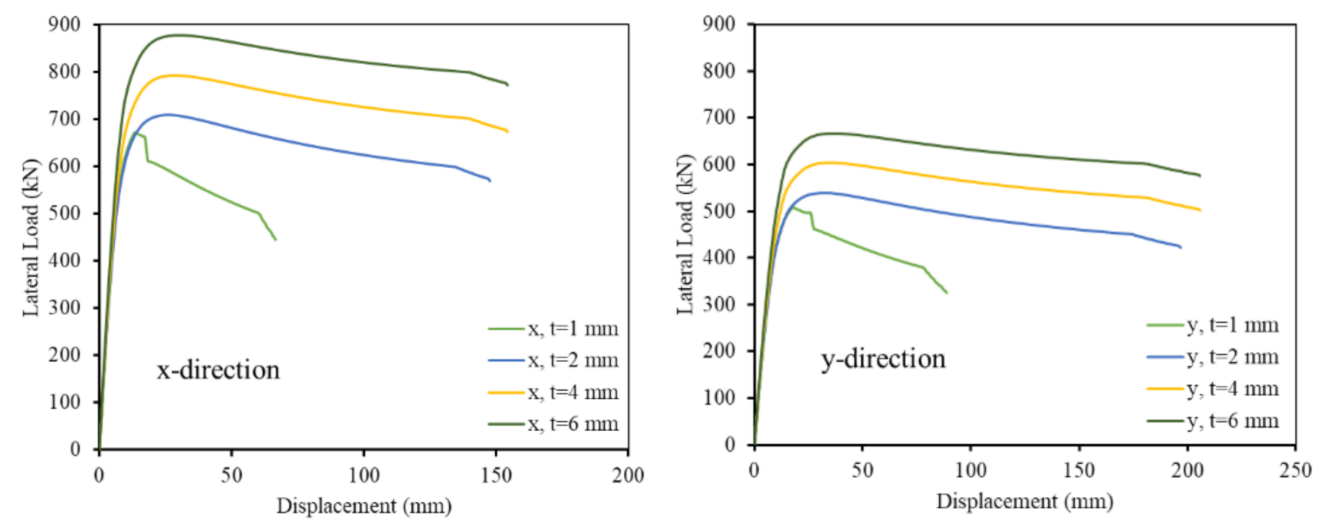

Figure 14. Lateral load-displacement curves according to the inner tube thickness (rectangular cross-section).

In the lateral load-displacement analysis, according to the change in the concrete strength, the lateral load increases in both directions when the confining effect of concrete occurs. The maximum lateral load of the confined $20 \mathrm{MPa}$ concrete is $150 \%$ and $140 \%$ of the unconfined $20 \mathrm{MPa}$ concrete in $x$ and $y$ directions, respectively. In addition, an increase in the maximum lateral load of the rectangular ICH RC columns increases the concrete strength. In the cases of varying the inner tube thickness, the maximum lateral force is increased in both $x$ and $y$ directions as the thickness is increased. The minimum inner tube thickness for avoiding the yield failure and bending failure is calculated as 1.89 and $0.47 \mathrm{~mm}$, respectively. As shown in Figure 14, when the inner tube thickness is $1 \mathrm{~mm}$, the lateral force of the column decreases sharply after a certain lateral displacement. That was because of the failure of the inner tube so that the confining effect of concrete does not occur. In the ICH RC column with a rectangular cross-section, the lateral load-displacement comparison between both directions shows that the maximum lateral force is larger for the longer side of the two directions. Figure 15 shows the lateral load-displacement of each member of the rectangular ICH RC column.

The results of the lateral load-displacement analysis for each member are equivalent to that of the case where the concrete strength and internal steel pipe thickness are selected to be $25 \mathrm{MPa}$ and $3 \mathrm{~mm}$, respectively. The maximum lateral force in the $x$ direction, which is longer than that in the $y$ direction, is larger. As the lateral displacement increases, the lateral load at the concrete part increases until the specific lateral displacement and then 
decreases. The cover concrete has no confining effect, and hence, the lateral load decreases sharply at the specific point and significantly affects the total lateral load.
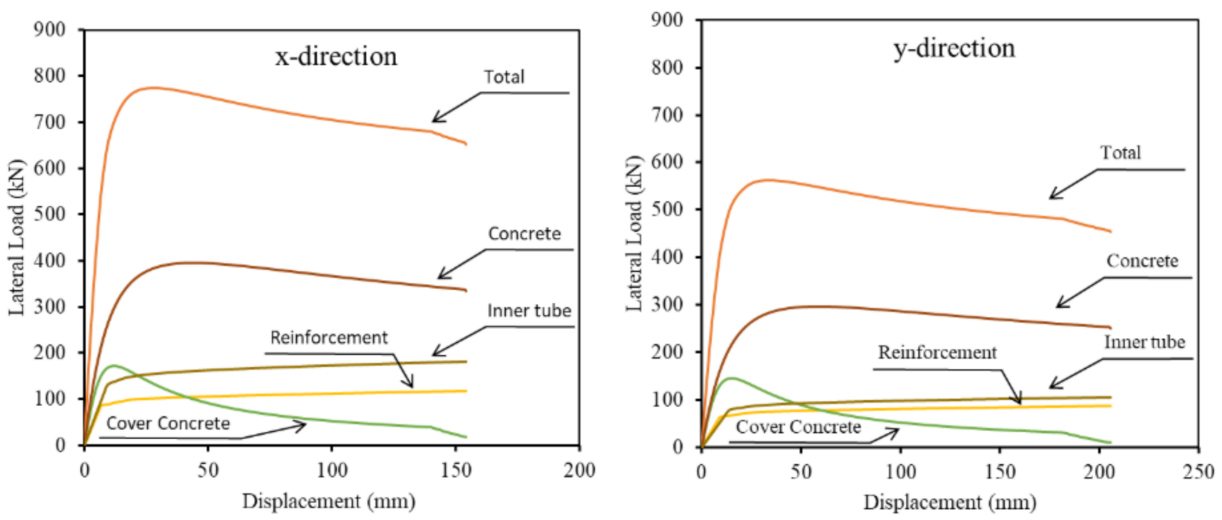

Figure 15. Lateral load-displacement of each member (rectangular cross-section).

\subsubsection{Square Cross-Section with Square Inner Tube}

Similar to the case of rectangular ICH RC columns, the behavior of the square ICH RC columns with the square inner tube (S-S ICH RC) is analyzed according to the variation in concrete strength and inner tube thickness by selecting the representative cross-sections of S-S ICH columns. Table 3 shows the material properties of the concrete and reinforcements used in the representative section and column members, as well as the dimensions of the columns.

Table 3. Cross-section and specification of the S-S ICH RC column.

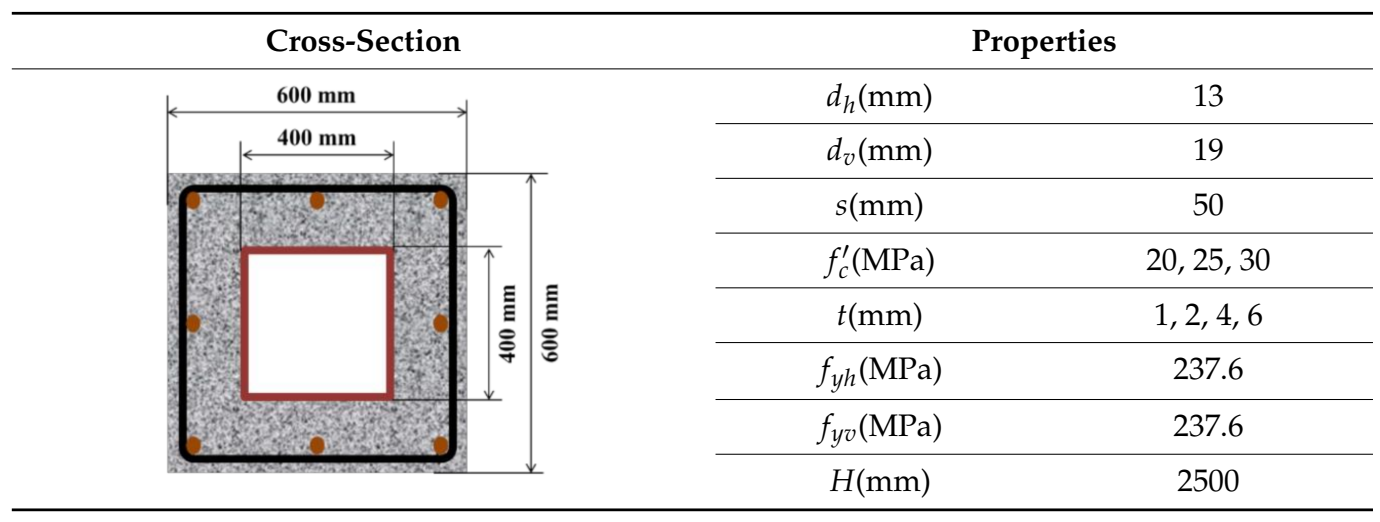

- Analysis of the axial load-bending moment

The analysis results of the S-S ICH RC column with different parameters are shown in Figures 16 and 17. Similar to the case of the rectangular ICH RC column, the unconfined concrete case, which uses $20 \mathrm{MPa}$ of concrete strength, is considered for confirming the confining effect of concrete. The cases with varying concrete strength use $3 \mathrm{~mm}$ of the inner tube thickness, and those with varying inner tube thickness use $25 \mathrm{MPa}$ of concrete. The initial axial load is assumed to be 0 , similar to the case of the rectangular ICH RC column.

Unlike the case of the rectangular ICH RC column, the analysis results are the same between the $x$ and $y$ directions in the case of the S-S ICH RC column, which has the same length in both vertical and horizontal directions. It is found that the resistance to axial load and bending moment increases when the confining effect of concrete occurs. With the same condition as $20 \mathrm{MPa}$ concrete strength, the column, considering the concrete confining effect, performed $126 \%$ and $122 \%$ of the column without the confining effect on the maximum lateral load and the maximum bending moment, respectively. In addition, it 
is confirmed that the column performance is improved as the concrete strength and inner tube thickness are increased.

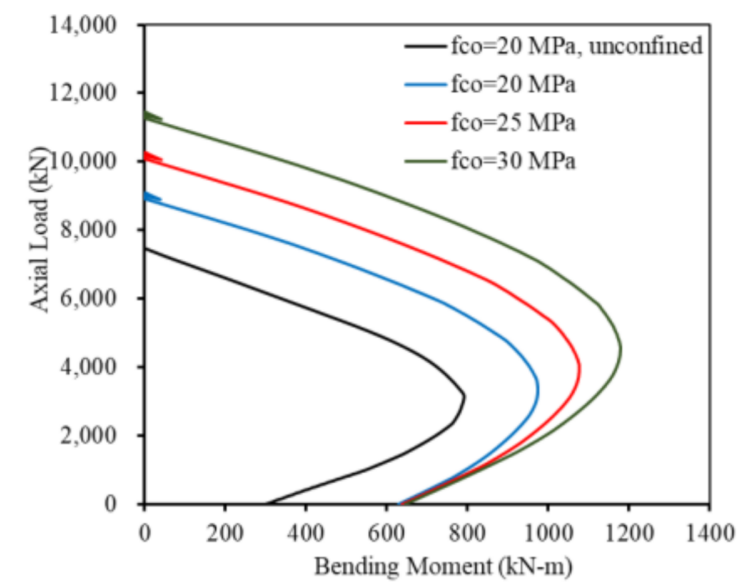

Figure 16. P-M interaction curves according to the concrete strength (S-S cross-section).

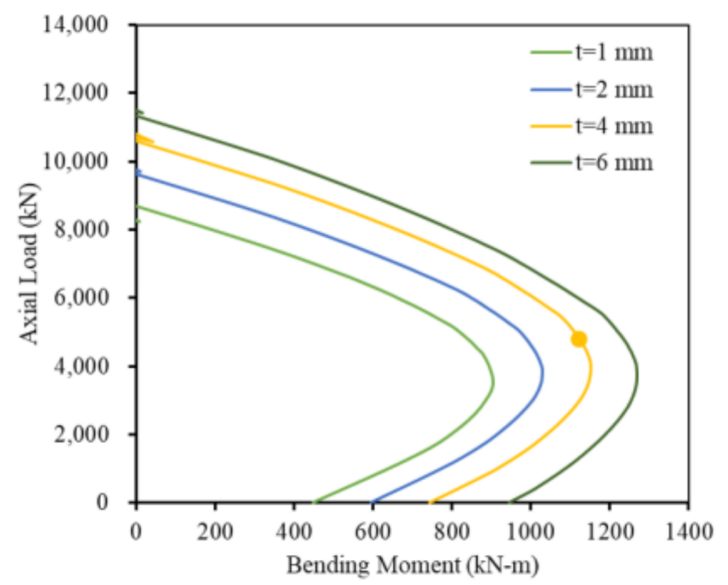

Figure 17. P-M interaction curves according to the inner tube thickness (S-S cross-section).

- Analysis of the lateral load-displacement

The analysis results of the S-S ICH RC column for the lateral load-displacement are represented in Figures 18 and 19.

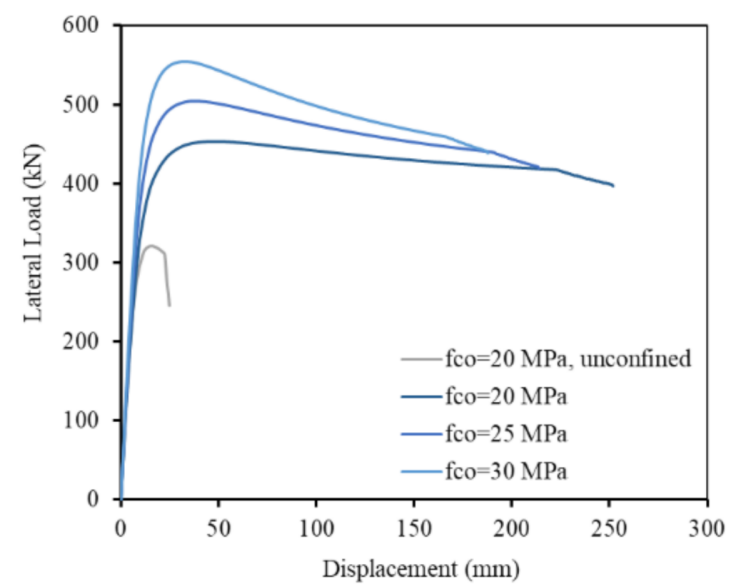

Figure 18. Lateral load-displacement curves according to concrete strength (S-S cross-section). 


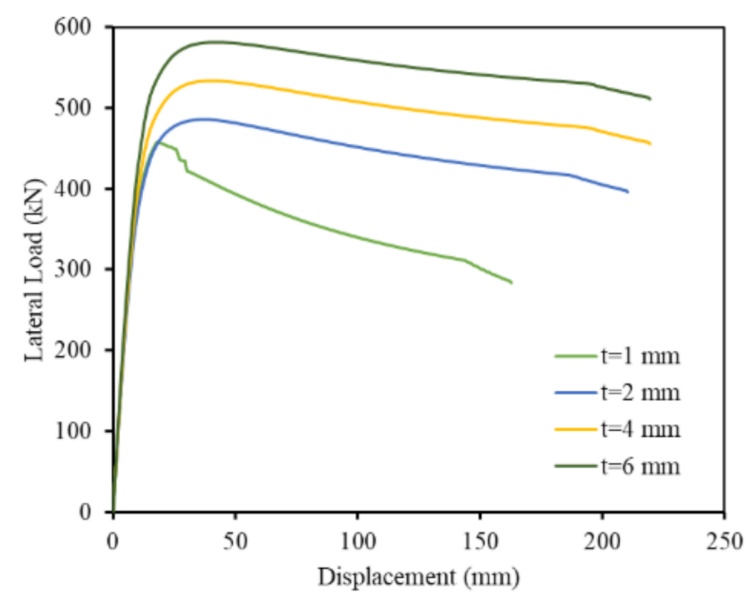

Figure 19. Lateral load-displacement curves according to the inner tube thickness (S-S cross-section).

The results of the lateral load-displacement analysis according to the change in the concrete strength also show that the maximum lateral load increases when the confining effect of concrete occurs. In addition, the lateral load increases with concrete strength. In the case of varying inner tube thickness, the maximum lateral load increases with an increase in thickness. The minimum inner tube thickness required to prevent the yielding and bending failure is 1.68 and $0.42 \mathrm{~mm}$, respectively. As shown in Figure 19, when the inner tube thickness is $1 \mathrm{~mm}$, the lateral load of the column decreases drastically because the inner tube failed so that the confining effect of concrete does not occur. Figure 20 shows the lateral load-displacement for each member of the S-S ICH RC column.

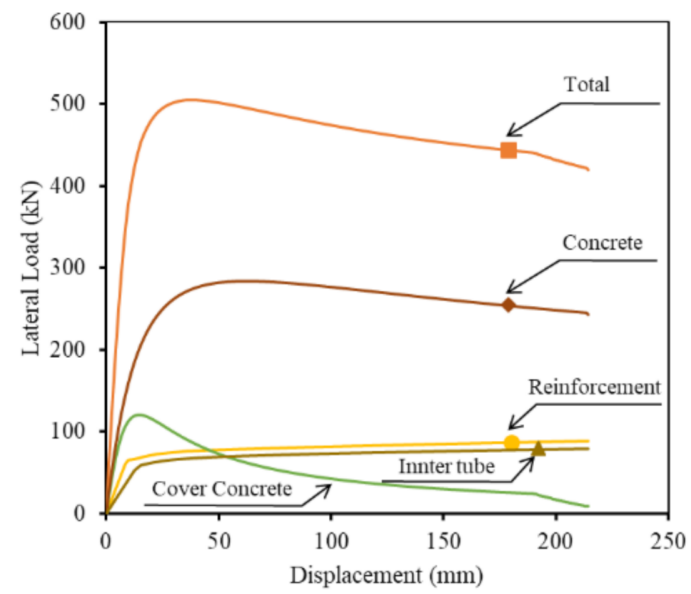

Figure 20. Lateral load-displacement of each member (S-S cross-section).

The lateral load-displacement analysis for each member is set with a concrete strength of $25 \mathrm{MPa}$ and inner tube thickness of $3 \mathrm{~mm}$. The lateral load of the inner tube is smaller than that of the longitudinal reinforcements, unlike the result of the rectangular ICH RC column. This is because the area of the inner tube in the S-S ICH RC column is narrower than that of the rectangular cross-section case. For the cover concrete, the lateral load decreases sharply after specific lateral displacement because the confining effect of concrete does not exist. Therefore, it is found that the effect of the concrete cover on the total column behavior is the largest.

\subsubsection{Square Cross-Section with Circular Inner Tube}

Similar to the previous cases, the behavior of the square ICH RC columns with the circular inner tube (S-C ICH RC) is analyzed according to the variation in concrete strength and inner tube thickness by using the representative cross-sections of S-C ICH columns in 
Table 4. This table shows the material properties of the concrete and reinforcements used in the representative section and column members, as well as the dimensions of the columns. All conditions are set the same as the case of the S-S ICH RC column, except for the shape of the inner tube.

Table 4. Cross-section and specification of the S-C ICH RC column.

\begin{tabular}{c|cc}
\hline \multicolumn{2}{c}{ Cross-Section } \\
\hline
\end{tabular}

- Analysis of the axial load-bending moment

Figures 21 and 22 demonstrate the results of the axial force-moment analysis of S-C ICH RC columns with various concrete strengths and inner tube thicknesses. The case of the unconfined concrete is considered, and the cases of the S-C ICH RC column are analyzed under the same conditions as those of the S-S ICH RC column, except the type of inner tube.

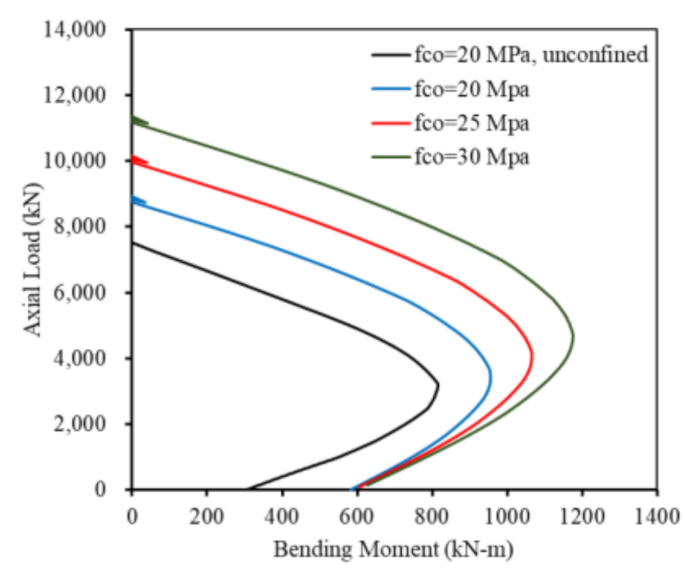

Figure 21. P-M interaction curves according to the concrete strength ( $\mathrm{S}-\mathrm{C}$ cross-section).

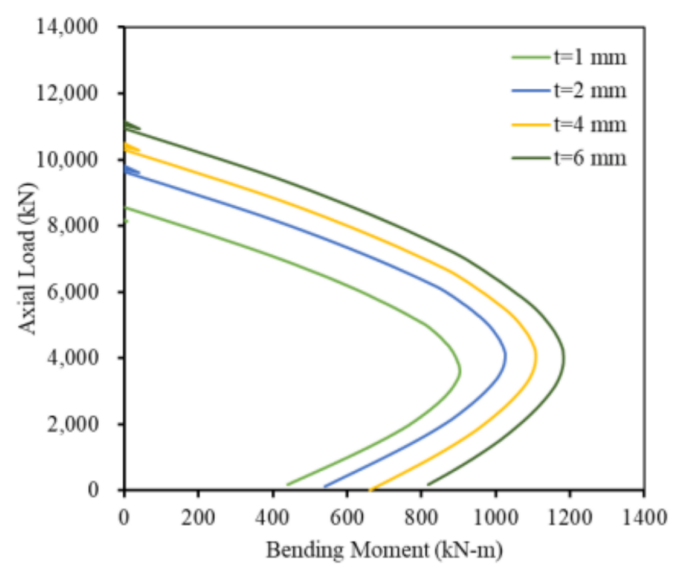

Figure 22. P-M interaction curves according to the inner tube thickness ( $\mathrm{S}-\mathrm{C}$ cross-section). 
We confirm that the resistance to axial load and bending moment increases when the confining effect of concrete occurs, as in the previous two cases. In addition, the maximum axial load and bending moment are found to increase with the concrete strength. In the case of varying inner steel pipe thickness, the resistance of the S-C ICH RC column with respect to the axial load and bending moment also increases with the inner tube thickness. Compared to the results of the S-S ICH RC column cases, those of the S-C ICH RC column cases show little difference.

- Analysis of lateral load-displacement

The analysis results of the S-C ICH RC column on the lateral load-displacement are displayed in Figures 23 and 24.

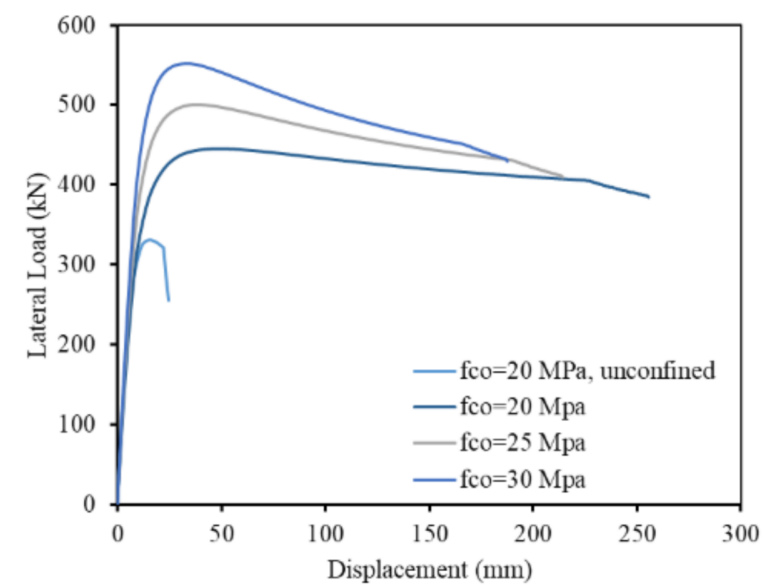

Figure 23. Lateral load-displacement curves according to concrete strength (S-C cross-section).

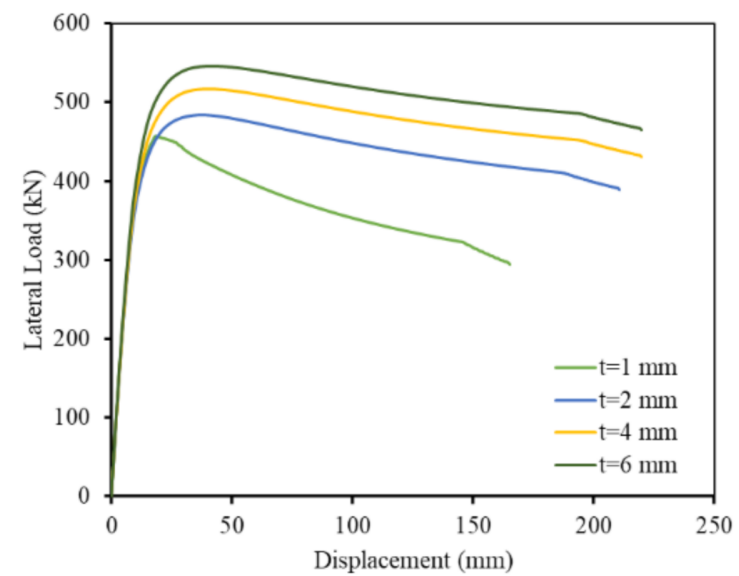

Figure 24. Lateral load-displacement curves according to inner tube thickness (S-C cross-section).

As a result of the analysis of the lateral load-displacement according to the concrete strength change, it is confirmed that the maximum lateral load increases by $132 \%$ when the confining effect of concrete occurs. In addition, the lateral load increases with the concrete strength and through the use of a thicker inner tube. The minimum thicknesses for avoiding the yield failure and buckling failure of the inner tube are calculated to be 1.68 and $1.47 \mathrm{~mm}$, respectively. As shown in Figure 24, when the inner tube thickness is $1 \mathrm{~mm}$, the lateral load of the column reduces sharply because the inner tube failed so that the confining effect of concrete does not occur. The decrease in the lateral load at a specific point is shown to be different from the previous case of the S-S ICH RC column and is considered to be caused by the difference in the area occupied by the concrete. Figure 25 shows the lateral load-displacement for each member of the S-C ICH RC column. 


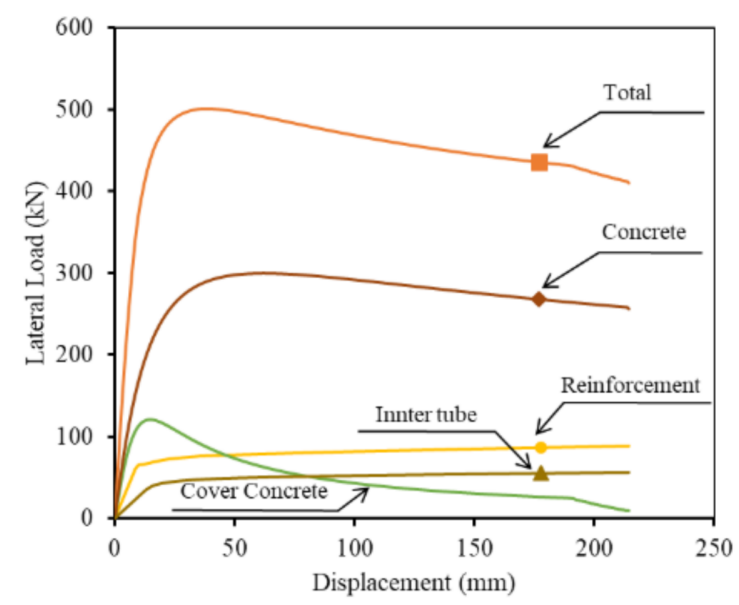

Figure 25. Lateral load-displacement of each member ( $\mathrm{S}-\mathrm{C}$ cross-section).

The results of the lateral load-displacement analysis for each member are the same as that of the case where the concrete strength and inner tube thickness are selected as $25 \mathrm{MPa}$ and $3 \mathrm{~mm}$, respectively. When comparing the results of S-S ICH RC and S-C ICH $\mathrm{RC}$ columns, the total lateral load is shown to be almost similar. However, the contribution of the total lateral load of the concrete and the inner tube in both S-S ICH RC and S-C ICH RC columns show differences. Since the area of the confining concrete in the S-C ICH $\mathrm{RC}$ column is larger than the case of the S-S ICH RC column, the contribution to the total lateral load from the concrete area in the S-C ICH RC column case is larger than the case of the S-S ICH RC column. On the contrary, the lateral force of the inner tube in the case of the S-C ICH RC column is relatively lower than that in the S-S ICH RC column case, because the inner tube occupies a smaller space in the S-C ICH RC column than that in the S-S ICH RC column.

\section{Conclusions}

The behavior of a polygonal ICH RC column was analyzed using a developed program. A nonlinear concrete model and a nonlinear column model for the polygonal ICH RC were suggested and verified by comparing the results with those of the experiments. The compared results showed an acceptable agreement of $6 \%$ of the total error average between the test results from the references and the analysis results. In addition, the column analysis results obtained according to the parameter changes showed that the suggested model is reasonable, and the confining effect of concrete must be considered for predicting the behavior of a polygonal ICH RC column. Three types of polygonal ICH RC columns, which have different cross-sections (rectangular, square with square inner tube, and square with circular inner tube), were analyzed. In the results of all analysis, the resistance ability against the axial force and the bending moment increased when the confining effect of concrete occurred. In addition, it was confirmed that the maximum axial load and bending moment increased not only with the concrete strength but also with the inner tube thickness. Similarly, in the lateral load-displacement analysis, the maximum lateral load was found to be proportional to the concrete strength and inner tube thickness. For the analysis results of each member, the contribution of the total column behavior was the greatest in the part of the cover concrete, which had no confining effect. A comparison between the S-S ICH RC and S-C ICH RC columns showed that they exhibit similar column behavior. In the result comparison of each member for both cases, however, it showed different contributions affecting the column behavior depending on the area of the concrete and inner tube. Therefore, the inner tube shape of the square ICH RC column could be decided depending on the economic situation of the members used for concrete and inner tube. The developed model can be used to select an appropriate cross-section and can contribute significantly to enhance the applicability of the polygonal ICH RC column to diverse structures. 
Author Contributions: Conceptualization, T.H.; methodology, T.H.; validation, S.K. and H.H.; investigation, S.K.; data curation, H.H.; writing-original draft preparation, S.K.; writing-review and editing, T.H.; visualization, S.K.; supervision, T.H.; project administration, T.H.; funding acquisition, T.H. All authors have read and agreed to the published version of the manuscript.

Funding: This research work was supported by the "Development of application technologies for ocean energy and harbor and offshore structures (KIOST Project Number: PE99931)".

Institutional Review Board Statement: Not applicable.

Informed Consent Statement: Not applicable.

Data Availability Statement: The data presented in this study are openly available in the references [19-23].

Conflicts of Interest: The authors declare no conflict of interest.

\section{Nomenclature}

$A_{s p} \quad$ cross-sectional area of a transverse reinforcement

$b_{c} \quad$ length of confined core concrete in $x$ direction

$b_{c i} \quad$ length of hollow section in $x$ direction

$C_{b} \quad$ distance between the neutral axis and the outer surface of the column

$C_{b, i} \quad$ distance between the neutral axis and the outer surface of the column at the $i$ th stage

$C_{b, i} \quad$ of the strain distribution

$D_{i} \quad$ diameter of hollow section

$d_{c} \quad$ length of confined core concrete in $y$ direction

$d_{c i} \quad$ length of hollow section in $y$ direction

$d_{h} \quad$ diameter of transverse reinforcement

$d_{v} \quad$ diameter of longitudinal reinforcement

$E \quad$ modulus of elasticity of internal steel tube

$E_{c} \quad$ tangent modulus of unconfined concrete

$F_{L, i} \quad$ lateral force at the $i$ th stage of the strain distribution

$F_{\text {initial initial axial load }}$

$f_{b k} \quad$ buckling strength of the internal tube

$f_{b t} \quad$ bending strength of the internal tube

$f_{b t-x} \quad$ bending strength of the internal tube in $x$ direction

$f_{b t-y} \quad$ bending strength of the internal tube in $y$ direction

$f_{c} \quad$ stress acting on concrete

$f_{c} \quad$ strength of unconfined concrete

$f_{\mathcal{C}} \quad$ strength of confined concrete

$f \prime_{c c} \quad$ confined strength of concrete

$f_{\text {comp }} \quad$ compression stress

$f_{l} \quad$ confining pressure

$f^{\prime} l_{l} \quad$ effective constant lateral confining pressure

$f_{l c} \quad$ confining stress on the concrete border

$f l_{l c} \quad$ effective constant lateral confining pressure on the concrete border

$f_{l c-x} \quad$ confining stress on the concrete border in $x$ direction

$f_{l c-y} \quad$ confining stress on the concrete border in $y$ direction

$f_{\text {lim }} \quad$ smaller value between yield strength and buckling strength of the internal tube

$f_{l r-x} \quad$ confining stress on the concrete body in $x$ direction

$f_{l r-y} \quad$ confining stress on the concrete body in $y$ direction

$f_{\text {tens }} \quad$ tension stress

$f_{\text {tube }} \quad$ stress acting on the internal tube

$f_{\text {tube }-x}$ stress acting on the internal tube in $x$ direction

$f_{\text {tube }-y} \quad$ stress acting on the internal tube in $y$ direction

$f_{u} \quad$ ultimate strength of the steel 


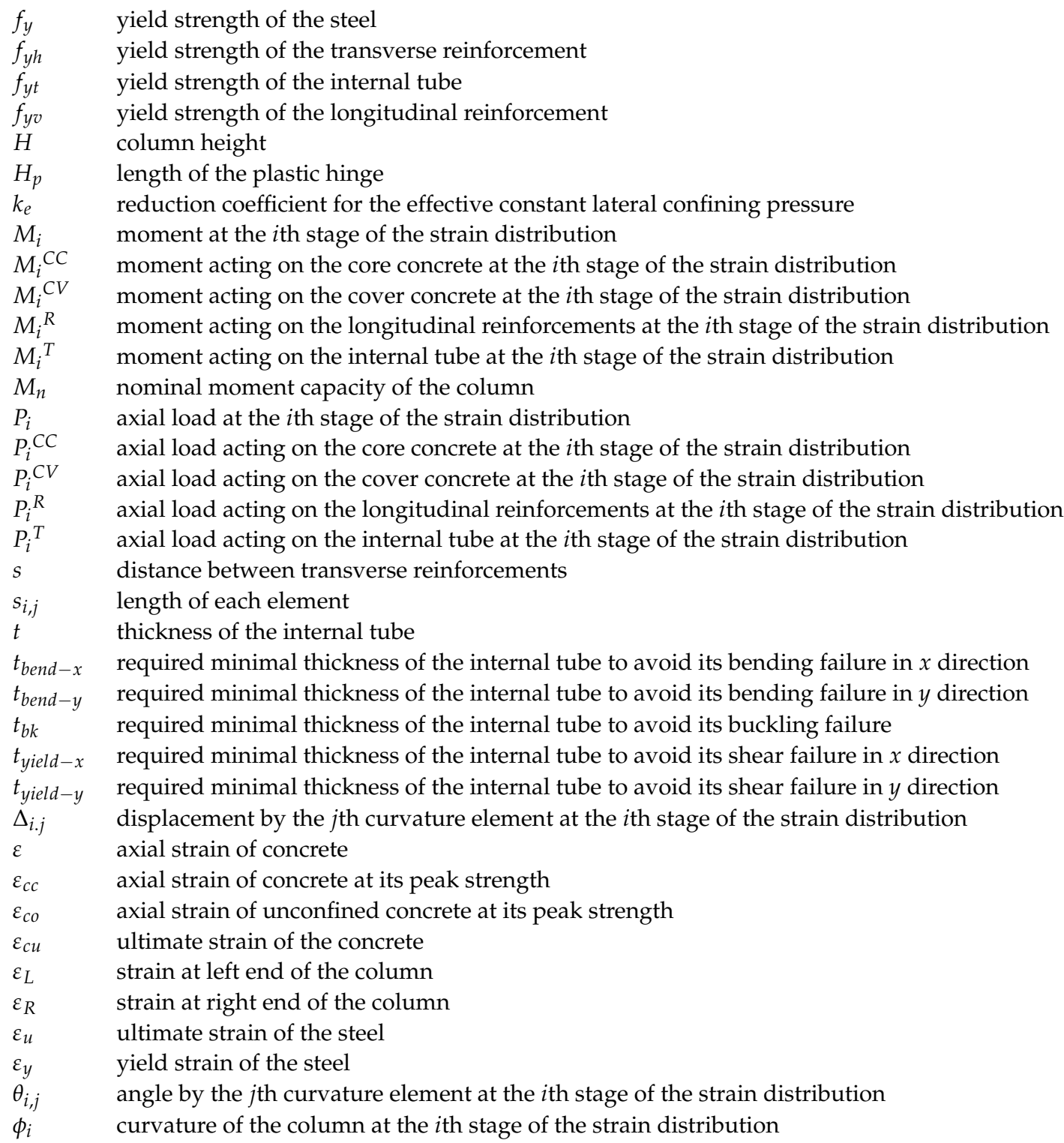

\section{References}

1. Gabel, J.; Shehadi, A. CTBUH Year in Review: Tall Trends of 2016: 2016 Another Record-Breaker for Skyscraper Completions; 18 "Tallest Titles" Bestowed. CTBUH J. 2017, 1, 38-45.

2. Tailor, A.; Dalal, S.P.; Desai, A.K. Comparative performance evaluation of steel column building \& concrete filled tube column building under static and dynamic loading. Procedia Eng. 2017, 173, 1847-1853.

3. Elshaer, A.; Bitsuamlak, G.T.; Damatty, A.E. Enhancing wind performance of tallbuildings using corner aerodynamic optimization. Eng. Struct. 2017, 136, 133-148.

4. Bai, Y.; Wang, J.; Liu, Y.; Lin, X. Thin-Walled CFST Columns for Enhancing Seismic Collapse Performance of High-Rise Steel Frames. Appl. Sci. 2017, 7, 53. [CrossRef]

5. Monteiro, A.; Arede, A.; Pouca, N.V. Seismic behavior of coupled column bridge RC piers: Experimental campaign. Eng. Struct. 2017, 132, 399-412. [CrossRef]

6. Guo, T.; Liu, J.; Huang, L. Investigation and control of excessive cumulative girder movements of long-span steel suspension bridges. Eng. Struct. 2016, 125, 217-226. [CrossRef]

7. Sritharan, S. Wind turbine towers: Precast concrete hexcrete may help increase renewable energy capacity with taller hub height. PCI J. 2015, 60, 33-38. [CrossRef]

8. Ma, Y.; Martinez-Vazquez, P.; Baniotopoulos, C. Wind turbine tower collapse cases: A historical overview. Proc. Inst. Civil Eng. Struct. Build. 2018, 172, 547-555. [CrossRef]

9. Wind Turbine Collapses in Ocotillo. Available online: http://www.eastcountymagazine.org/wind-turbine-collapses-ocotillo (accessed on 15 October 2019). 
10. Wind Turbine Collapses in Haskell County. Available online: https://www.wind-watch.org/news/2014/12/16/wind-turbinecollapses-in-haskell-county/ (accessed on 13 October 2019).

11. Han, T.H.; Lim, N.H.; Han, S.Y.; Park, J.S.; Kang, Y.J. Nonlinear concrete model for an internally confined hollow reinforced concrete column. Mag. Concrete Res. 2008, 60, 429-440. [CrossRef]

12. Kim, S.; Kim, J.J.; Han, T.H. Section design of internally confined hollow reinforced concrete wind power tower. J. Korean Soc. Hazard Mitig. 2016, 16, 163-174. [CrossRef]

13. Han, T.H.; Stallings, J.M.; Kang, Y.J. Behaviour of a hollow RC column with an internal tube. Mag. Concrete Res. 2010, 62, 25-38. [CrossRef]

14. American Wood Council. Beam Design Formulas with Shear and Moment Diagrams; American Forest \& Paper Association: Washington, DC, USA, 2007.

15. Kerr, A.D.; Soifer, M.T. The linearization of the prebuckling state and its effect on the determined instability loads. J. Appl. Mech. 1969, 36, 775-783. [CrossRef]

16. Mander, J.B.; Priestley, M.J.N.; Park, R. Seismic Design of Bridge Piers; Research Report No. 84-2; University of Canterbury: Christchurch, New Zealand, 1984.

17. Popovics, S. A numerical approach to the complete stress-strain curves of concrete. Cem. Concr. Res. 1973, 3, 583-599. [CrossRef]

18. Kilpatrick, A.E.; Ranagan, B.V. Deformation-Control Analysis of Composite Concrete Columns; Research Report No. 3/97; School of Civil Engineering, Curtin University of Technology: Perth, Australia, 1997.

19. Yatsumoto, H.; Sakai, J.; Hoshikuma, J. Cyclic Loading Test of Reinforced Concrete Column with Hollow Section an High Longitudinal Steel Ratio under High Axial Loading. In Proceedings of the 28th U.S.-Japan Bridge Engineering Workshop, Portland, OR, USA, 8-10 October 2012.

20. Ko, S.H. Seismic performance of square RC column confined with spirals. JKSMI 2012, 16, 88-97.

21. Seo, S.Y.; Yoon, S.J.; Lee, W.J. Evaluation of structural performance the hollow PC column joint subjected to cyclic lateral load. J. Korea Concr. Inst. 2008, 20, 335-343.

22. Ang, B.G. Ductility of Reinforced Concrete Bridge Piers under Seismic Loading. Master's Thesis, University of Canterbury, Christchurch, New Zealand, 1981.

23. Ohno, T.; Nishioka, T. An experimental study on energy absorption capacity of columns in reinforced concrete structures. Doboku Gakkai Ronbunshu 1984, 1, 137-147. [CrossRef] 